\title{
BMJ Open Epidemiological characteristics of HIV infection among college students in Nanjing, China: a cross-sectional survey
}

Wei Li (D) , ${ }^{1}$ Jinjin Chu, ${ }^{1}$ Zhengping Zhu (D) , ${ }^{2}$ Xin Li, ${ }^{2}$ You Ge, ${ }^{1}$ Yan He, ${ }^{1}$ Qian Ni, ${ }^{1}$ Taha Musa, ${ }^{1}$ Xiaoshan $\mathrm{Li}^{3}{ }^{3}$ Pingmin $\mathrm{Wei}^{1}$
To cite: Li W, Chu J, Zhu Z, et al. Epidemiological characteristics of HIV infection among college students in Nanjing, China: a crosssectional survey. BMJ Open 2020;10:e035889. doi:10.1136/ bmjopen-2019-035889

- Prepublication history and additional material for this paper are available online. To view these files, please visit the journal online (http://dx.doi. org/10.1136/bmjopen-2019035889).

Received 22 November 2019

Revised 24 March 2020

Accepted 07 April 2020

Check for updates

(c) Author(s) (or their employer(s)) 2020. Re-use permitted under CC BY-NC. No commercial re-use. See rights and permissions. Published by BMJ.

${ }^{1}$ Teaching and Research Office of Epidemiology and Health Statistics, School of Public Health, Southeast University, Nanjing, Jiangsu, China ${ }^{2}$ Section of AIDS and STDs Control and Prevention, Nanjing Municipal Center for Disease Control and Prevention, Nanjing, Jiangsu, China

${ }^{3}$ Department of Lung Transplant Center, Nanjing Medical

University Affiliated Wuxi

People's Hospital, Wuxi, Jiangsu, China

Correspondence to

Dr Pingmin Wei;

mpw1963@126.com

\section{ABSTRACT}

Objective This study aimed to investigate the epidemiological characteristics and HIV/AIDS-related knowledge, attitudes and practice (KAP) among HIV-positive college students.

Design A cross-sectional study.

Setting Five districts of Nanjing, China.

Participants A total of 156 college students with newly diagnosed HIV infection between September 2015 and July 2017.

Main outcome measures Social-demographic

characteristics, mode of HIV acquisition, infection of sexually transmitted diseases, risky sexual behaviours and HIV/AIDSrelated KAP were collected by a face-to-face questionnaire administered by trained interviewers.

Results About 98.7\% (154/156) of HIV-positive college students in our study were men, and $96.1 \%(148 / 154)$ of them were infected by sexual intercourse with men. More than half $(52.5 \%, 82 / 156)$ of participants were freshmen or sophomores. Nearly $30 \%$ (44/154) of male students did not realise the severe status of the HIV/AIDS epidemic among students who are men who have sex with men (MSM). More than four-fifths of male students did not know if their male regular $(83.0 \%, 93 / 112)$ or casual $(95.9 \%, 94 / 98)$ sexual partners were HIV-positive, while less than half of them had high-risk perceptions towards HIV infection from male regular and occasional sexual partners. Approximately one-half and four-fifths of male students had more than two regular $(54.5 \%, 61 / 112)$ and occasional $(79.6 \%, 78 / 98)$ partners during lifetime, respectively. However, only $62.5 \%$ (70/112) and $66.3 \%$ (65/98) of male students used condoms consistently during sexual intercourse with regular and casual partners, respectively. Geosocial networking apps have become the most dominant way for male students to seek sexual partners.

Conclusions This study reported a low level of HIV/ AIDS-related knowledge, a high level of exposure to risky sexual behaviours and some valuable epidemiological characteristics among HIV-positive college students, which highlighted the importance of carrying out HIV/AIDS prevention education and risk warning education early and timely towards college students on campus.

\section{INTRODUCTION}

Approximately 37.9 million people were living with HIV/AIDS at the end of 2018 worldwide, and 1.7 million people became newly infected with HIV in 2018. Of 5000 individuals who

\section{Strengths and limitations of this study}

The first study investigating the HIV/AIDS-related knowledge, attitudes and practice (KAP) among HIVpositive college students in China.

- Face-to-face questionnaires administered by trained interviewers in a separate private room to ensure privacy and confidentiality for the respondents and achieve satisfactory response rates.

- Possible overestimation of the HIV/AIDS-related knowledge levels due to the postdiagnostic measures of HIV/AIDS-related KAP.

- A cross-sectional study with small sample size and short time frame may not be generalisable to other regions or populations.

were newly infected cases with HIV each day in 2018, around $32 \%$ were young people aged 15-24 years old. ${ }^{1}$ The UNICEF reported that the estimated number of adolescents (10-19 years) living with HIV/AIDS has increased by 480000 from 2000 to 2018 globally, among whom 380000 were male adolescents. About 740000 adolescents could become infected with HIV between 2016 and 2030 due to the low level of knowledge regarding HIV/AIDS and high-risk sexual behaviours if current prevention progress is not optimised. ${ }^{2}$

In recent years, the number of people living with HIV/AIDS has been increased sharply among young people in China, especially in college students. According to the National Centre for AIDS/STD Control and Prevention, China Centers for Disease Control and Prevention (CDC), the number of newly diagnosed college students has seen an annual growth rate ranging from $30 \%$ to $50 \%$ over the past several years, ${ }^{3}$ and nearly 10 college students were infected with HIV each day. ${ }^{4}$ From 2013 to 2017, 12037 new cases of HIV infection among young students were reported in China, and $97.7 \%$ of them were men. ${ }^{5}$ In 2017, the newly diagnosed students reached 3,077, which was tenfold greater 
than 10 years ago. ${ }^{6}$ The proportion of men who have sex with men (MSM) among students was higher than that of adolescents outside school. ${ }^{7-9}$ Among 38 million university students in China, ${ }^{10}$ approximately 1.7 million are MSM aged 18-22 years. ${ }^{11}$ Therefore, the prevalence of HIV infection among college students has become a worrisome issue and prevention efforts are needed urgently.

As an important educational centre, there are 53 institutions of higher education and nearly 780000 college students in Nanjing city. ${ }^{12}$ In recent years, students have captured considerable public health attention as an increasing number of them have been detected with HIV. Over 200 college students were diagnosed in Nanjing between 2002 and 2014. ${ }^{13}$ Our previous study reported that a total of 319 young students were diagnosed with HIV in Nanjing between 2011 and 2016 and and the average growth rate was $33.9 \%$ during the 6 years ${ }^{14}$. The proportion of HIV-infected MSM among young student cases $(93.4 \%)$ was higher than that of adolescents outside school $(77.8 \%) .{ }^{14}$ However, we have little knowledge of the epidemiological characteristics and HIV/AIDSrelated knowledge, attitudes and practice (KAP) among HIV-positive college students in Nanjing, China. There is a critical need to study the detailed characteristics of this population.

\section{Significance and objectives of the study}

College students in China already face a number of challenges, and now HIV has been added to this list. ${ }^{4}$ Understanding the characteristics of HIV-infected college students could assist in identifying effective interventions to deal with the HIV epidemic on campus. In addition, evaluating HIV/AIDS-related KAP among HIV-positive college students rather than young students in general, could help retrospect the process of infection in college students and provide more useful information for HIV prevention on this population. ${ }^{15-18}$ Due to the critical gap between the increasing prevalence of HIV and the limited workforce in CDC in China, the data collected through routine surveillance systems were ineffective to provide sufficient information about the characteristics of HIVinfected college students. Therefore, in this study, we conducted a cross-sectional survey by a structured questionnaire, aiming to better understand the epidemiological characteristics and HIV/AIDS-related KAP among HIV-positive college students.

\section{METHODS}

\section{Study area and period}

This study was conducted from 1 September 2015, to 31 July 2017, in five counties (including Gulou, Xuanwu, Jiangning, Qinhuai and Qixia) of Nanjing, Jiangsu province, China. Of 53 institutions of higher education in Nanjing city, 45 are located in these five districts. Based on the unpublished data from Nanjing CDC, the number of HIV-infected students in these five districts accounted for over $90 \%$ of the total number of HIV-positive students in Nanjing over the past few years.

\section{Study participants}

All newly diagnosed HIV-positive individuals were recruited consecutively if they met the following criteria: (1) HIV-positive cases screened by HIV-1/HIV-2 ELISA and confirmed by HIV-1 Western blot in Nanjing CDC between 1 September 2015 and 31 July 2017; (2) selfreported as undergraduates or postgraduates and was confirmed by the student cards/identification card/residence permit; (3) aged 18 years and above; (4) agreed to participate in this study with verbal or written informed consents. Eventually, 156 HIV-positive students were enrolled in the survey.

\section{Study instrument}

Data were collected using a structured intervieweradministered questionnaire. This questionnaire was developed based on the Guidelines of intervention work for the prevention of HIV/AIDS among MSM and heterosexual in China (issued by National Center for AIDS/ STD Control and Prevention, China CDC) and took the characteristics of the young students into consideration. In our presurvey, this questionnaire showed high reliability and good internal consistency in measuring the HIV/AIDSrelated KAP among college students (Cronbach's $\alpha$ is 0.762 and Kaiser-Meyer-Olkin is 0.843).

Three categories of indicators, including sociodemographic characteristics, information of infection and HIV/AIDS-related KAP, were collected. Socio-demographic indicators included gender, age, ethnicity, domicile, educational institution and year in college. Information on infection was consisted of the mode of HIV acquisition and detection, and the self-reported infection of sexually transmitted diseases (STDs). HIV/AIDS-related knowledge was measured by eight items, which were specially developed for college students by the National Center for AIDS/STD Control and Prevention, China CDC. ${ }^{19}$ For each item, the correct answer ('yes') was scored 1, with the wrong answer ('no' or 'unknown') scored as 0 . The total score of the HIV/AIDS-related knowledge was 8, with a higher score indicating a higher level of HIV/AIDS-related knowledge. Attitudes regarding HIV/AIDS prevention were measured by two questions, including whether the respondents knew the HIV-infection status of their sexual partners and whether or not they were worried about being infected with diseases from sexual partners. Sexual behaviour indicators included the types of sexual partners (eg, male and female regular sexual partner, male and female casual sexual partner), the way to seek sexual partners, the frequency of sexual behavioursand condom usage (online supplementary questionnaire).

\section{Data collection}

The interview was conducted at the first follow-up after the confirmation of HIV infection. Data were collected 
through face-to-face questionnaire administered by trained staff who have long been engaged in HIV/AIDS prevention and control in each district CDC. All investigators were trained for questionnaire investigation and data collection to reduce information bias. The interview was conducted in a separate private room to protect the privacy of the respondents. Each interview took approximately $20-40 \mathrm{~min}$.

\section{Patient and public involvement}

Patients were involved in the questionnaire investigation. The Nanjing CDC was involved in the study design. The questionnaire investigation was conducted by staff from district CDCs of Nanjing in a separate private room located in each district CDC.

\section{Statistical analysis}

Data analysis was performed using SPSS V.24.0 for windows. Quantitative data were calculated as means $\pm \mathrm{SD}$, and qualitative data were presented by absolute number and percentage (n (\%)).

\section{RESULTS}

\section{Socio-demographic and infection characteristics}

From 1 September 2015 to 31 July 2017, a total of 159 HIV-infected college students were confirmed in Nanjing. One male case declined to participate in the study, and another two patients (one man and one woman) did not belong to our survey area (five counties), resulting in 156 individuals enrolled in our study. The mean age of the 156 participants was $21.3 \pm 2.3$ years (range $18-33$ ). The majority of participants $(98.7 \%, 154 / 156)$ were men, and only $1.3 \%(2 / 156)$ were women. Almost all (96.1\%, $148 / 154$ ) of male students were infected through sexual intercourse with men. The majority of participants were sophomore students $(37.8 \%, 59 / 156)$, whereas freshmen, junior, senior and postgraduate students accounted for $14.7 \%$ (23/156), $17.3 \%$ (27/156), $19.9 \%$ (31/156) and $10.3 \%$ (16/156), respectively. Only $19.2 \%(30 / 156)$ of students were natives, while $22.4 \%(35 / 156)$ and $58.3 \%$ $(91 / 156)$ were migrants from other cities in Jiangsu and other provinces, respectively. The proportion of active detection after high-risk behaviours accounted for $32.1 \%$ (50), while $67.9 \%$ (106) was discovered by passive detection. A total of 40 (25.6\%) participants had self-reported STDs, including 17 (10.9\%) syphilis, 17 (10.9\%) condyloma acuminate, $4(2.6 \%)$ gonorrhoea and 2 (1.3\%) genital herpes (table 1).

\section{The level of knowledge regarding HIV/AIDS among HIV- infected male students}

The overall mean score of knowledge regarding HIV/ AIDS among male students was $6.7 \pm 0.1$. The accuracy of responses for the eight items ranged from $67.5 \%$ to $96.8 \%$, with four items below $80 \%$. Fifty $(32.5 \%)$ participants did not know that the new-type drugs (eg, methamphetamine, ecstasy, ketamine etc.) can increase HIV
Table 1 The social-demographic characteristics and information of infection of 156 HIV-positive students

\begin{tabular}{|c|c|c|}
\hline Characteristics & $\begin{array}{l}\text { Participants } \\
\text { (n) }\end{array}$ & $\%$ \\
\hline \multicolumn{3}{|l|}{ Gender } \\
\hline Female & 2 & 1.3 \\
\hline Male & 154 & 98.7 \\
\hline \multicolumn{3}{|l|}{ Age (years) } \\
\hline $18-19$ & 27 & 17.3 \\
\hline$\geq 20$ & 129 & 82.7 \\
\hline \multicolumn{3}{|l|}{ Ethnicity } \\
\hline Han & 152 & 97.4 \\
\hline Non-Han & 4 & 2.6 \\
\hline \multicolumn{3}{|l|}{ Domicile } \\
\hline Nanjing & 30 & 19.2 \\
\hline Other cities in Jiangsu & 35 & 22.5 \\
\hline Other provinces & 91 & 58.3 \\
\hline \multicolumn{3}{|l|}{ Grade } \\
\hline Freshman & 23 & 14.7 \\
\hline Sophomore & 59 & 37.8 \\
\hline Junior & 27 & 17.3 \\
\hline Senior & 31 & 19.9 \\
\hline Postgraduate & 16 & 10.3 \\
\hline \multicolumn{3}{|l|}{ Mode of HIV acquisition } \\
\hline Sexual intercourse with men & 148 & 94.9 \\
\hline Male heterosexual behaviour & 6 & 3.8 \\
\hline Female heterosexual behaviour & 2 & 1.3 \\
\hline \multicolumn{3}{|l|}{ The way of diagnosis } \\
\hline $\begin{array}{l}\text { Active detection after high-risk } \\
\text { behaviours }\end{array}$ & 50 & 32.1 \\
\hline Medical & 33 & 21.1 \\
\hline Blood donation & 24 & 15.4 \\
\hline STDs detection & 15 & 9.6 \\
\hline Health examination & 12 & 7.7 \\
\hline Preoperation detection & 10 & 6.4 \\
\hline Others & 12 & 7.7 \\
\hline \multicolumn{3}{|l|}{ STDs } \\
\hline Syphilis & 17 & 10.9 \\
\hline Gonorrhoea & 4 & 2.6 \\
\hline Condyloma acuminatum & 17 & 10.8 \\
\hline Genital herpes & 2 & 1.3 \\
\hline No & 116 & 74.4 \\
\hline
\end{tabular}

STDs, sexually transmitted diseases.

infection, and 44 (28.8\%) individuals did not realise the severe status of HIV/AIDS epidemic among MSM in colleges in China (At present, the HIV/AIDS epidemic among young students in China is growing rapidly, and MSM are primarily afflicted, followed by heterosexual individuals). In addition, $24.0 \%$ (37) of individuals did 
Table 2 Risk perceptions towards HIV infection among 154 HIV-positive male students

\begin{tabular}{|c|c|c|c|c|}
\hline Risk perception & $\begin{array}{l}\text { Male regular } \\
\text { partners } \\
(112 \\
\text { respondents), } \\
\mathrm{N}(\%)\end{array}$ & $\begin{array}{l}\text { Male casual } \\
\text { partners } \\
\text { (98 } \\
\text { respondents), } \\
\mathrm{N}(\%)\end{array}$ & $\begin{array}{l}\text { Female regular } \\
\text { partners } \\
\text { (13 } \\
\text { respondents), } \\
\mathrm{N}(\%)\end{array}$ & $\begin{array}{l}\text { Female casual } \\
\text { partners } \\
\text { (9 respondents), } \\
\mathrm{N}(\%)\end{array}$ \\
\hline $\begin{array}{l}\text { Knowing sexual partner had been infected during sexual } \\
\text { intercourse with partners }\end{array}$ & $19(17.0)$ & $4(4.1)$ & $0(0.0)$ & $2(22.2)$ \\
\hline $\begin{array}{l}\text { Worrying about being infected with diseases by sexual } \\
\text { partners }\end{array}$ & $44(39.3)$ & $46(46.9)$ & $3(23.1)$ & $2(22.2)$ \\
\hline
\end{tabular}

not know that HIV/AIDS is one of the serious and incurable diseases, and $22.1 \%$ (34) of subjects did not know that HIV/AIDS patients have equal rights for marriage, employment and education (online supplementary table S1).

\section{Risk perceptions towards HIV infection among HIV-infected male students}

Among the 154 HIV-positive male students, 112 (72.7\%), $98(63.6 \%), 13(8.4 \%)$ and $9(5.8 \%)$ respondents reported having sexual intercourse with male regular, male casual, female regular and female casual partners, respectively. The proportions of participants knowing that their sexual partner had been infected with HIV were extremely low (table 2). Among these respondents, only a low proportion of individuals reported that they were worried about being infected with diseases from partners (table 2). The predominant reason for not worrying about being infected with diseases was that they did not realise the potential risk (figure 1).

\section{Sexual behaviors among HIV-infected male students}

One hundred and forty-five male students reported on the experience of the initial sexual intercourse. The mean age for the initial experience of sexual intercourse was $19.1 \pm 2.0$ years (range 12-33), and $37.7 \%(59 / 145)$ was before 18 years old. Four-fifths $(80.7 \%)$ of the respondents reported that the partner of first sexual intercourse was man, and $37.8 \%(55 / 145)$ did not use condoms during the initial sexual intercourse.

Of respondents who have had male regular and casual partners, $54.5 \%(61 / 112)$ and $79.6 \%$ (78/98) had more than two sexual partners during lifetime, respectively. The proportions of male students who had intercourse over two times per month with male regular and casual partners were $61.6 \%(59 / 112)$ and $30.6 \%$ (30/98), respectively. However, the proportions of using condoms consistently during sexual intercourse with partners were low. The predominant reason for not using condoms was not realising the necessity of using condoms in sexual intercourse (figure 2). Geosocial networking (GSN) apps have become the primary way for students to seek sexual partners (table 3).

\section{DISCUSSIONS}

The severity of the HIV/AIDS epidemic among college students has captured increasing attention of the Chinese government. Several interventions, including expanding the publicity of HIV/AIDS-related knowledge, sex and reproductive health education, making HIV testing more accessible on campuses, and offering adolescent peer education programmes on HIV/AIDS, have been taken to address the HIV epidemic on campus. ${ }^{320}$ However, the current interventions for preventing HIV/AIDS are

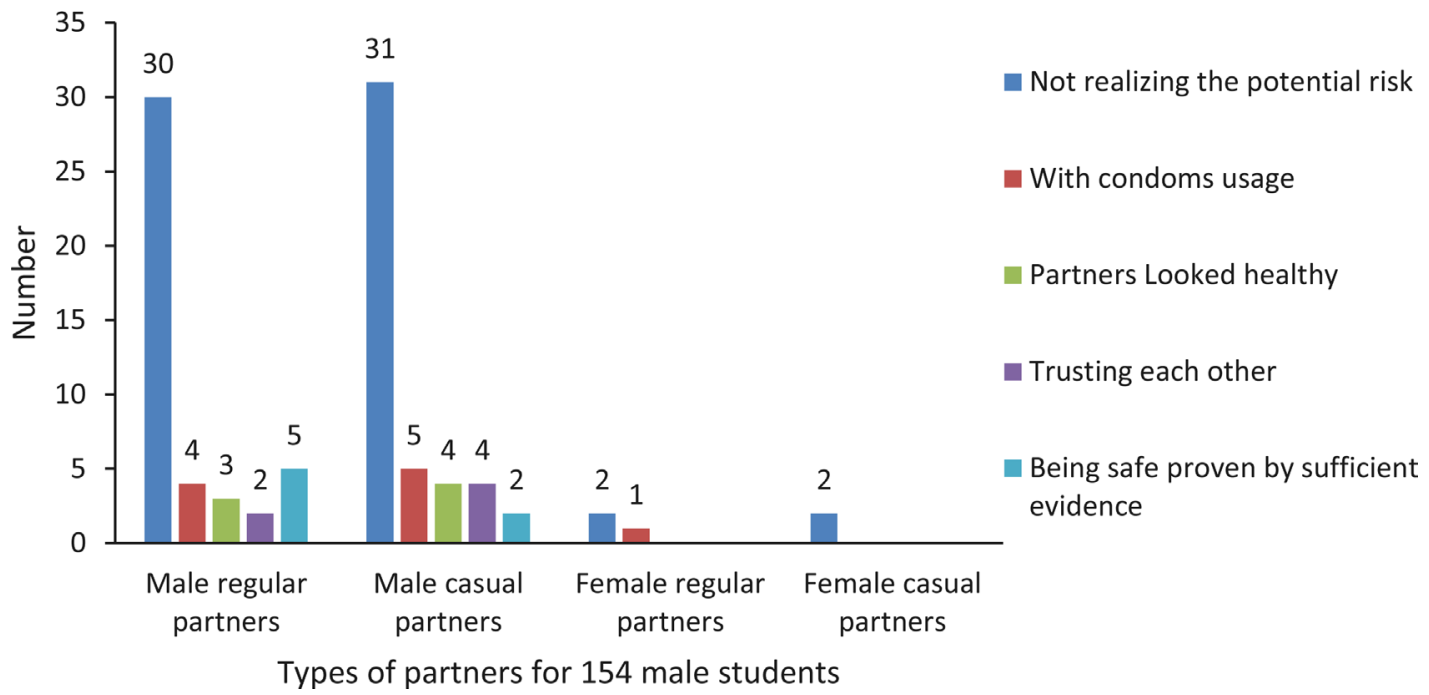

Figure 1 The reasons for not worrying about being infected with diseases during sexual intercourse among 154 male students. 


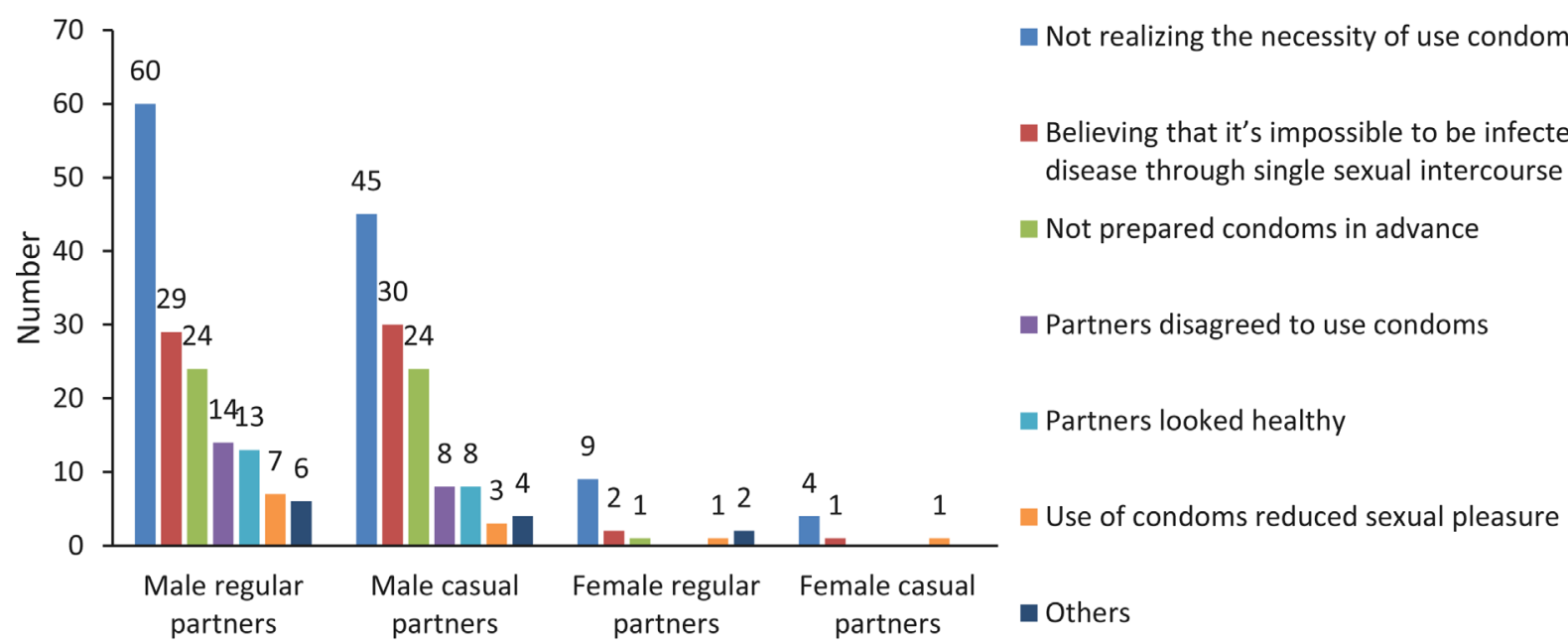

Types of partners for 154 male students

Figure 2 The reasons for not using condoms during sexual intercourse among 154 male students.

not provided in all universities and are implemented ineffectively. ${ }^{3}$ Sex education programmes are not wellimplemented among a substantial proportion of nearly 2800 universities in China, and only a small number of colleges made HIV testing more accessible on campus. Thus, how to implement these strategies effectively has become critical for HIV/AIDS prevention and control among college students. In this study, for the first time, we described the epidemiological characteristics of HIV infection among HIV-positive college students and explored the potential factors that underlying the increasing HIV infection in students.
Previous studies reported that college students had a high level of HIV/AIDS-related knowledge as they were highly educated. ${ }^{21} 22$ However, in this study, we found that there was still some lack of knowledge about HIV/ AIDS, since the accuracy rates of half of HIV/AIDSrelated questions were below $80 \%$ among HIV-positive male students. Specifically, a considerable proportion of individuals did not know the serious status of HIV/ AIDS epidemic among students who are MSM. If college students did not receive comprehensive sex education before sexually active, they would be highly vulnerable to HIV when they started having sexual intercourse. Because

Table 3 Characteristics of sexual behaviours among 154 HIV-positive male students

\begin{tabular}{|c|c|c|c|c|}
\hline Characteristics & $\begin{array}{l}\text { Male regular } \\
\text { partners } \\
\text { (112 respondents), } \\
\mathrm{N}(\%)\end{array}$ & $\begin{array}{l}\text { Male casual } \\
\text { partners } \\
\text { (98 respondents), } \\
\mathrm{N}(\%)\end{array}$ & $\begin{array}{l}\text { Female regular } \\
\text { partners } \\
\text { (13 respondents), } \\
\mathrm{N}(\%)\end{array}$ & $\begin{array}{l}\text { Female casual } \\
\text { partners } \\
\text { (9 respondents), } \\
\mathrm{N}(\%) \\
\end{array}$ \\
\hline \multicolumn{5}{|l|}{ The numbers of sexual partners } \\
\hline 1 & $51(45.5)$ & $20(20.4)$ & $13(100.0)$ & $3(33.3)$ \\
\hline $2-5$ & $60(53.6)$ & 65 (66.3) & $0(0.0)$ & $6(66.6)$ \\
\hline$\geq 6$ & $1(0.9)$ & $13(13.3)$ & $0(0.0)$ & $0(0.0)$ \\
\hline \multicolumn{5}{|l|}{ The way to seek sexual partners } \\
\hline Geosocial networking apps & $92(82.1)$ & $89(90.8)$ & $1(7.7)$ & $4(44.4)$ \\
\hline Students or friends & $17(15.2)$ & $6(6.1)$ & $12(92.3)$ & $2(22.2)$ \\
\hline Others & $3(26.8)$ & $3(3.1)$ & $0(0.0)$ & $3(33.3)$ \\
\hline \multicolumn{5}{|c|}{ Frequency of intercourse (times per month) } \\
\hline 1 & $43(38.4)$ & $68(69.4)$ & $9(69.2)$ & $7(77.8)$ \\
\hline $2-5$ & $52(46.4)$ & $28(28.6)$ & $4(30.8)$ & $2(22.2)$ \\
\hline$\geq 6$ & $7(6.3)$ & $2(2.0)$ & $0(0.0)$ & $0(0.0)$ \\
\hline \multicolumn{5}{|l|}{ Condom usage } \\
\hline Consistently & $70(62.5)$ & $65(66.3)$ & $4(30.8)$ & $4(44.4)$ \\
\hline Sometimes & $31(27.7)$ & $19(19.4)$ & $6(46.2)$ & 3 (33.3) \\
\hline Rarely & $11(9.8)$ & $14(14.3)$ & $3(23.1)$ & $2(22.2)$ \\
\hline
\end{tabular}


the competition for the college entrance examination is fierce in China, precollege education is mainly focused on scholarly studies with minimal sex education. ${ }^{23}$ For many college freshmen, knowledge about HIV/AIDS, STIs and sexual health are extremely limited, and they do not know the serious status of the HIV/AIDS epidemic among young students either. Some students have had risky sexual behaviours before they received adequate awareness of disease prevention. Thus, comprehensive HIV/AIDS and sex education should be carried out early and timely to improve the level of HIV/AIDS-related knowledge among students. Not only educators in the schools but also parents in the families should take on the responsibility for fostering an open environment for education and awareness on HIV/AIDS for students. Meanwhile, peer-education also has the potential to improve awareness and enhance students' motivation for HIV protection.

After entering university, students have increased exposure to various sexual partners without parents' supervision, and tend to have sexual intercourse more frequently with multiple sexual partners as compared with before attending university. ${ }^{24}$ Some students with limited knowledge and awareness on sex education might be exposed to frequent unprotected sexual behaviours. Unfortunately, our findings revealed that a large number of male students did not know if their sexual partners were HIV-positive people and never realised that they could be infected with diseases through their sexual partners. The low level of risk perceptions towards HIV infection among male students might be a crucial factor for their risky sexual behaviour. Thus, there is a need to strengthen the warning education about risky sexual behaviours for college students. Furthermore, HIV infection presented in all grades of colleges in our study, indicating that the risk-warning education should be informed throughout the college stage. However, at present, some universities in China are unable to disseminate HIV/AIDS-related knowledge and implement sex education with an open and accepting attitude. ${ }^{26}$ Thus, college administrators must create an open environment where sex education can be frequently accessed by students and awareness on HIV/AIDS can be sufficiently improved. Simultaneously, education sectors need to work together with public health professionals and student organisations to conduct education campaigns in a more engaging way.

The high-risk behaviours, for instance, bisexual intercourses, multiple sex partners, high frequency of intercourse and rare usage of condoms among college students in Nanjing were similar to those reported in non-infected students. ${ }^{27}{ }^{28}$ We found that the rate of active HIV test was low, probably due to the ongoing impact of stigma and discrimination associated with HIV infection. Across 19 countries with available data, about $20 \%$ of people living with HIV avoided going to a clinic or hospital for HIV testing, treatment and prevention services, because they worried about stigma or discrimination related to their HIV status. ${ }^{29}$ The small proportion of active detection among students also indicated the lack of self-motivation for HIV testing and highlighted the importance of readily accessible means of testing on campus. Some community organisations have provided on-site HIV testing and anonymous HIV urine-testing services in universities, ${ }^{30}$ which should be implemented nationwide.

A recent study reported that the use of GSN apps was associated with higher HIV incidence among MSM in China. ${ }^{31}$ In this study, we found that approximately $82.1 \%$ and $90.8 \%$ of male students used GSN Apps to seek the male regular and casual partners, suggesting that the GSN apps might also play an increasingly critical role in promoting the spread of HIV on campus, which was in line with other studies in USA and Europe. ${ }^{32-35}$ Yang et al reported that several GSN apps including Blued, Aloha and Zank were used widely for recognising sexual partners among Chinese MSM undergraduates. ${ }^{36}$ Unfortunately, many GSN apps have not played a corresponding role in disseminating knowledge regarding HIV/AIDS. The other issue among college students was the coinfection of HIV and STDs. The survey showed that the prevalence of syphilis was posing a sharp increase among young Chinese MSM. ${ }^{3738}$ On the one hand, multiple infection of STDs, especially syphilis and condyloma acuminate infection, may increase HIV-1 RNA levels, enhancing the transmissibility of HIV-1 among college students. ${ }^{39}$ On the other hand, HIV-1 may affect the clinical presentation, treatment outcome and progression of STDs. ${ }^{40}$ Therefore, both the measures of STDs prevention and treatment these HIV-positive individuals should be conducted on campus simultaneously.

Our study has some limitations. First, selection bias may exist as some HIV-positive college students concealed that they were attending colleges for the consideration of privacy. Thus, our data may not be fully representative of the epidemiological characteristics of HIV infection among college students in Nanjing. Second, participants may be unable to provide precise information on the experience of the first sexual intercourse they occurred many years ago, resulting in information bias. Participants tended to have underreported on some sensitive information, such as sexual behaviour. In addition, participants tended to improve their levels of HIV/AIDS-related knowledge after diagnosis of HIV infection, leading to the overestimated accuracy rates of HIV/AIDS-related knowledge questions. Third, we did not collect data on the availability and accessibility of treatment and information regarding issues of stigma and discrimination, which could be conducted in the future survey.

\section{CONCLUSIONS}

This study reported a low level of HIV / AIDS-related knowledge, a high level of exposure to risky sexual behaviours and some valuable epidemiological characteristics among HIV-positive male college students in Nanjing, China. A considerable proportion of HIV-positive male students did not know the serious status of the HIV/AIDS 
epidemic among students who are MSM and had a low level of risk perceptions towards HIV infection. Comprehensive sex education should be carried out early and timely among Chinese students to improve the level of HIV/AIDS-related knowledge. Risk-warning education is needed throughout the college stage to enhance the awareness of HIV/AIDS prevention and to reduce risky sexual behaviours among college students. Furthermore, the GSN apps should be fully used in programmes for HIV prevention given GSN apps have become the main tool for college students to seek sexual partners.

Acknowledgements We would like to thank Kexin Zhu for language polishing for the manuscript. The authors gratefully acknowledge the college students in Nanjing who took part in this study, further acknowledgement of the staff in Jiangsu CDC, Nanjing CDC for patient recruitment, and blood sample collection.

Contributors PW and XL were responsible for funding acquisition and project administration; WL and JC were major contributors in writing: original draft; ZZ was responsible for the resources; $\mathrm{XL}$ and $\mathrm{YH}$ contributed to the investigation; $Y G$ and QN helped in data curation and formal analysis; XL and THM contributed to the writing: review and editing. All authors read and approved the final version of the manuscript.

Funding This work was supported by the Humanities, and Social Sciences of Ministry of Education Planning Fund of China (no. 16YJA840014), which played an important role in designing the study and ensuring this study proceeded smoothly.

\section{Competing interests None declared.}

Patient and public involvement Patients and/or the public were not involved in the design, or conduct, or reporting, or dissemination plans of this research.

\section{Patient consent for publication Not required.}

Ethics approval This study was reviewed and approved by the Human Research Ethics Committee of the Zhongda hospital affiliated Southeast University, China (Approval ID: 2017ZDKYSB045). The objectives and the procedure of the study, and the potential risks and benefits of participating in the study were told to potential participants during the recruitment. Verbal or written consent procedures were obtained from participants and they had the right to discontinue the survey at any time.

Provenance and peer review Not commissioned; externally peer reviewed.

Data availability statement Data are available upon reasonable request. mpw1963@126.com.

Open access This is an open access article distributed in accordance with the Creative Commons Attribution Non Commercial (CC BY-NC 4.0) license, which permits others to distribute, remix, adapt, build upon this work non-commercially, and license their derivative works on different terms, provided the original work is properly cited, appropriate credit is given, any changes made indicated, and the use is non-commercial. See: http://creativecommons.org/licenses/by-nc/4.0/.

ORCID iDs

Wei Li http://orcid.org/0000-0003-0769-5805

Zhengping Zhu http://orcid.org/0000-0003-3201-299X

\section{REFERENCES}

1 UNAIDS. UNAIDS-data-2018, 2018. Available: https://www.unaids. org/sites/default/files/media_asset/unaids-data-2018_en.pdf

2 UNICEF. For every child, end AIDS: seventh stocktaking report, 2016, 2016. Available: https://www.unicef.org/publications/index_93427. html

3 Li G, Jiang Y, Zhang L. Hiv upsurge in China's students. Science 2019;364:711.

4 Zou H, Tucker JD, Fan S, et al. Learning about HIV the hard way: HIV among Chinese MSM attending university. Lancet Infect Dis 2018;18:16-18.

5 Han J, Mao YR, Tang HL, et al. [Initial follow-up and CD(4)(+) T cell count test of newly reported students HIV cases in China, 20132017]. Zhonghua Yu Fang Yi Xue Za Zhi 2018;52:1254-8.
6 CDC C. A regular news conference of China's National health Commission, 2018. Available: http://ncaids.chinacdc.cn/zxzx/mtsd3/ 201811/t20181123_197487.htm

7 Fu L, Zhang X, Li Z, et al. Hiv/Aids epidemic among young students in Nanchang City, 2008-2016. Chinese Journal of School Health 2018;39:585-7.

8 Li N, Fan P, Ma Y, et al. The study of the HIV epidemic among young students aged 15-24 in Henan Province, China. Modern Preventive Medicine 2015;42:1729-31.

9 Hu R, Luo L, Xu J, et al. A descriptive and comparative analysis of HIV/AIDS epidemic between young students and out-ofschool youths in Wuhan. Chinese Journal of Social Medicine 2019;36:268-71.

10 CHINA MOETPSRO. Educational statistics in 2017, 2017. Available: http://en.moe.gov.cn/documents/statistics/2017/national/

11 Devakumar D, Bamford A, Ferreira MU, et al. Infectious causes of microcephaly: epidemiology, pathogenesis, diagnosis, and management. Lancet Infect Dis 2018;18:e1-13.

12 Overview of education development of Nanjing City in 2018 Available: http://edu.nanjing.gov.cn/zwgk/tjsjjjd/201904/t20190412_ 1506528.html

$13 \mathrm{Xu} \mathrm{Y,} \mathrm{Zhu} \mathrm{Z,} \mathrm{Wu} \mathrm{S,} \mathrm{et} \mathrm{al.} \mathrm{Hiv/Aids} \mathrm{epidemic} \mathrm{status} \mathrm{among} \mathrm{young}$ students in Nanjing City during 2002-2014. Chinese Journal of AIDS and STD 2015;21:893-4.

$14 \mathrm{Xu} \mathrm{Y,} \mathrm{Li} \mathrm{X,} \mathrm{Wu} \mathrm{S,} \mathrm{et} \mathrm{al.} \mathrm{Epidemiological} \mathrm{characteristics} \mathrm{of} \mathrm{HIV}$ infection among population aged 18-24 years from 2011-2016 in Nanjing. chinese Journal of School Health 2018;39:1202-5.

$15 \mathrm{Xu} \mathrm{J}$, Zhou C, Hu Z. Analysis of AIDS knowledge, attitude and behavior(KAB) among university students in China. Chinese Journal of School Health 2014;35:487-9.

16 Wang X, Li L, Hu Y. Investigation and analysis of AIDS- related knowledge, attitude and behavior among young students in Xiamen. China Tropical Medicine 2015;15:37-40.

17 Gao Y, Wang H, Qi Q, et al. Status of AIDS Knowledge,Attitude and Behavior of College Students and Health Education for Them in Inner Mongolia. Chinese General Practice 2011;14:782-4.

18 Chang J, Lu W. Knowledge attitudes and practices regarding HIV / AIDS among MSM college students in Guiyang City. Chinese Journal of School Health 2014;35:500-2.

19 The core knowledge of AIDS prevention and treatment for young students. Available: http://ncaids.chinacdc.cn/qsnazbfk/allin/xzzx/ 201701/P020170109434770367618.pdf

$20 \mathrm{Li} \mathrm{S}$, Huang H, Cai Y, et al. Evaluation of a school-based HIV/AIDS peer-led prevention programme: the first intervention trial for children of migrant workers in China. Int J STD AIDS 2010;21:82-6.

$21 \mathrm{Ma} \mathrm{W}$, Wu G, Zheng $\mathrm{H}$, et al. Prevalence and risk factors of HIV and syphilis, and knowledge and risk behaviors related to HIV/AIDS among men who have sex with men in Chongqing, China. J Biomed Res 2016;30:101-11.

22 Samkange-Zeeb FN, Spallek L, Zeeb H. Awareness and knowledge of sexually transmitted diseases (STDs) among school-going adolescents in Europe: a systematic review of published literature. BMC Public Health 2011;11:727.

23 Qi L. Research on sex education of students of senior middle schools:taking two senior middle schools in Research on sex education of students of senior middle schools:taking two senior middle schools in Zhejiang province as examples. The Chinese Journal of Human Sexuality 2017;26:154-7.

24 Torres RMC, Cruz MMda, Périssé ARS, et al. High HIV infection prevalence in a group of men who have sex with men. Braz $\mathrm{J}$ Infect Dis 2017;21:596-605.

$25 \mathrm{Xu} \mathrm{H}$, Xie J, Xiao Z, et al. Sexual attitudes, sexual behaviors, and use of HIV prevention services among male undergraduate students in Hunan, China: a cross-sectional survey. BMC Public Health 2019;19:250

26 Chi X, Yu L, Winter S. Prevalence and correlates of sexual behaviors among university students: a study in Hefei, China. BMC Public Health 2012;12:972.

27 Kann L, Olsen Emily O'Malley, Kinchen S, et al. HIV-Related Risk Behaviors Among Male High School Students Who Had Sexual Contact with Males - 17 Large Urban School Districts, United States, 2009-2013. MMWR Morb Mortal Wkly Rep 2016;65:106-9.

28 Zhu Z, Xu Y, Wu S, et al. The epidemiological survey of HIV and syphilis infection among young men who have sex with men. Chinese Journal of disease control and prevention 2018;22:1265-9.

29 UNAIDS. Unaids warns that HIV-related stigma and discrimination is preventing people from accessing HIV services, 2017. Available: https://www.unaids.org/en/resources/presscentre/pressrelease andstatementarchive/2017/october/20171002_confrontingdiscrimination 
30 Lichtenstein B, Barber BW, West Alabama A. A partnership approach to providing on-site HIV services for probationers and parolees: a pilot study from Alabama, USA. J Int AIDS Soc 2016;19:20868.

$31 \mathrm{Xu} \mathrm{J}, \mathrm{Yu} \mathrm{H}$, Tang W, et al. The effect of using Geosocial networking Apps on the HIV incidence rate among men who have sex with men: Eighteen-Month prospective cohort study in Shenyang, China. J Med Internet Res 2018;20:e11303.

32 Wana GW, Arulogun O, Roberts A, et al. Predictors of risky sexual behaviour among pre-college students in Adama town, Ethiopia. Pan Afr Med J 2019;33:135.

33 Nagaddya R, Kiconco S, Komuhangi A, et al. Assessing the Influence of Social Networking Material on Adolescents' Sexual Behavior in Kampala. Journal of Education and Practice 2017;8:187-93.

34 Cookingham LM, Ryan GL. The impact of social media on the sexual and social wellness of adolescents. J Pediatr Adolesc Gynecol 2015;28:2-5.

35 Landry M, Turner M, Vyas A, et al. Social media and sexual behavior among adolescents: is there a link? JMIR Public Health Surveill 2017;3:e28.

36 Yang S, Li C, Zhang J, et al. Present situation and influencing factors of university MSM students in search of sexual partner via
MSM dating software in Chendu. Chinese Journal of HIV and STD 2018;24:66-9.

37 Ruan Y, Jia Y, Zhang X, et al. Incidence of HIV-1, syphilis, hepatitis $B$, and hepatitis $C$ virus infections and predictors associated with retention in a 12-month follow-up study among men who have sex with men in Beijing, China. J Acquir Immune Defic Syndr 2009;52:604-10.

38 Xu J-J, Reilly KH, Lu C-M, et al. A cross-sectional study of HIV and syphilis infections among male students who have sex with men (MSM) in northeast China: implications for implementing HIV screening and intervention programs. BMC Public Health 2011;11:287.

39 Chen M-J, Scheer S, Nguyen TQ, et al. Hiv co-infection among persons diagnosed with sexually transmitted diseases, San Francisco, 2007-2014. Sex Transm Dis 2018. doi:10.1097/ OLQ.0000000000000789

40 Chun HM, Carpenter RJ, Macalino GE, et al. The role of sexually transmitted infections in HIV-1 progression: a comprehensive review of the literature. J Sex Transm Dis 2013;2013:1-15. 